\title{
EFICIÊNCIA DO USO DE NITROGÊNIO EM PLANTAS TRANSGÊNICAS DE TABACO COM ALTO ACÚMULO DE PROLINA
}

Eliane Batista Viudes, Flaive Loyse Baldassarini Silva, Alessandra Ferreira Ribas, Luiz Gonzaga Esteves Vieira, Carlos Henrique Santos, Ana Cláudia Pacheco

Universidade do Oeste Paulista - UNOESTE, Curso de Agronomia, Presidente Prudente, SP. E-mail: anaclau@unoeste.br

\section{RESUMO}

O aumento da eficiência de uso do nitrogênio nas plantas cultivadas é resultado da melhoria nos mecanismos envolvidos na absorção, translocação, assimilação e remobilização do nitrogênio. Nesse estudo, plantas de tabaco com alto acúmulo de prolina causado pela inserção do gene mutante VaP5CSF129A sob controle do promotor constitutivo CaMV 35 S foram utilizadas como modelo para investigar o efeito da superexpressão do transgene na absorção e utilização de nitrogênio. Para tanto, foi conduzido um experimento em casa de vegetação, em delineamento inteiramente casualizado, em arranjo fatori9al $2 \times 5$, formado por dois genótipos (evento transgênico e controle não transformado) e cinco doses de adubação nitrogenada (25, 50,100, 200 e $400 \mathrm{~kg} \mathrm{ha}^{-1}$ de nitrogênio). As plantas foram avaliadas quanto à altura, número de folhas, massa seca, teor de prolina livre, teores de nitrogênio e de proteína total; além das eficiências de absorção (EAbs), utilização (EUtil) e uso (EUN) do nitrogênio aplicado. As plantas do evento transgênico com alto acúmulo de prolina foram menos eficientes que as plantas controle em termos de absorção de nitrogênio, apresentando menores teores de nitrogênio nas folhas, raiz e na planta inteira, o que resultou em menor EAbs nessas plantas. Não houve diferença na eficiência de utilização de nitrogênio entre os genótipos transgênico e o controle. No entanto, as plantas transgênicas apresentaram menor EUN em comparação às plantas controle. Concluiu-se que plantas de tabaco transgênicas com alto acúmulo de prolina não apresentam potencial de utilização direta em sistemas agrícolas, uma vez que a alteração do balanço bioquímico entre os metabolismos de nitrogênio e carbono não resultou em plantas com maior eficiência de uso do nitrogênio.

Palavras-chave: amônio; assimilação de nitrogênio; biomassa; nitrato.

\section{NITROGEN USE EFFICIENCY IN TRANSGENIC TOBACCO PLANTS WITH HIGH ACCUMULATION OF PROLINE}

\begin{abstract}
Increasing the nitrogen use efficiency of crop plants is a result of the improvement in the mechanisms involved in nitrogen uptake, translocation, assimilation and remobilization. In this study, tobacco plants with high accumulation of proline caused by the insertion of the VaP5CSF129A mutant gene under control of the constitutive promoter CaMV $35 \mathrm{~S}$ was used as a model to investigate the effect of overexpression of the transgene in the uptake and utilization of $\mathrm{N}$. For this, an experiment was carried out in a completely randomized design, in a 2x5 factorial arrangement, with two genotypes (transgenic event and untransformed control) and five levels of nitrogen fertilization $\left(25,50,100,200\right.$ and $\left.400 \mathrm{~kg} \mathrm{~N} \mathrm{ha}{ }^{-1}\right)$, cultivated under greenhouse conditions. Plants were evaluated for height, number of leaves, dry mass, free proline content, nitrogen content, total protein content and use of the applied $\mathrm{N}$ (efficiency of absorption EAbs, efficiency of leaf utilization - EUtil and efficiency of plant use - EUN). The transgenic plants with high proline accumulation were less efficient than the control plants in terms of nitrogen absorption (with lower $\mathrm{N}$ levels in root, leaves and whole plant), which resulted in lower EAbs. There was no difference between the transgenic and control genotypes for EUtil. However, the transgenic plants presented lower EUN in comparison to the control plants. Our data showed that transgenic tobacco plants with high proline accumulation do not have potential for direct use in agricultural systems, since the alteration of the biochemical balance between the metabolisms of nitrogen and carbon did not result in plants with higher EUN.
\end{abstract}

Keywords: ammonium; $\mathrm{N}$ assimilation; biomass; nitrate. 


\section{INTRODUÇÃO}

$\mathrm{O}$ fornecimento adequado e a disponibilidade de nitrogênio (N) são essenciais para o metabolismo das plantas (LAWLOR, 2002). O N é necessário para a síntese de grande número de compostos vitais para a célula vegetal, como ATP, NADH, NADPH, enzimas (HARPER, 1994), aminoácidos, proteínas, ácidos nucléicos, poliaminas, clorofilas e outros constituintes celulares (LEA, 1993; RUIZ et al., 1999). Dada a sua importância e devido à sua alta mobilidade no solo, o $\mathrm{N}$ tem sido intensamente estudado, no sentido de maximizar a sua absorção e utilização pela planta, além de se procurar diminuir as perdas de $\mathrm{N}$ no solo (BREDEMEIER; MUNDSTOCK, 2000).

A eficiência de uso do nitrogênio (EUN), em geral, é representada pelo produto da eficiência de absorção do nitrogênio (EAbs), que é definida como a capacidade da cultura em absorver o $\mathrm{N}$ disponível no solo (MOLL et al., 1982), e a eficiência de utilização do nitrogênio (EUtil), que é a capacidade da cultura em assimilar o $\mathrm{N}$ absorvido para a produção de grãos, frutos, folhas, etc. Em teoria, para melhorar a EUN é necessário melhorar a EAbs e/ou a EUtil (GOOD et al., 2007).

Pesquisas foram realizadas visando melhorar a absorção, assimilação, remobilização e regulação do $\mathrm{N}$ na planta através da transgenia, pela expressão de genes que codificam enzimas relacionadas ao metabolismo do nitrogênio, tais como a alanina aminotransferase (AlaAT) (SHRAWAT et al., 2008), glutamina sintetase (GS) (BRAUER et al., 2011), NADH-glutamina oxoglutarato aminotransferase (NADH-GOGAT) (CHICHKOVA et al., 2001), NADP(H)-glutamato desidrogenase (NADP(H)-GDH) (ABIKO et al., 2010), aspartato aminotransferase (AspAT) (ZHOU et al., 2009) e asparagina sintetase (AS) (LAM et al., 2003). A expressão de outros genes, incluindo aqueles envolvidos na relação carbono/nitrogênio $(C / N)$ e sinalização, também pode exercer papel importante na melhoria da EUN (MCALLISTER et al., 2012).

Estudos mais aprofundados com modificações de genes e proteínas envolvidos na assimilação de $\mathrm{N}$, tais como a alanina aminotransferase (AlaAT), demonstraram impactos sobre a EUN (MCALLISTER et al., 2012). Esta enzima catalisa uma transaminação reversível entre piruvato e glutamato, como o doador amino para produzir alanina e 2oxoglutarato (MUENCH; GOOD, 1994). Os substratos e os produtos de AlaAT são todos importantes componentes do metabolismo de $\mathrm{N}$ e de carbono (C) na planta. Sendo assim, a melhoria da EUN por superexpressão do gene AlaAT foi demonstrada em plantas de arroz (SHRAWAT et al., 2008) e canola (GOOD et al., 2007) cultivadas em condições limites de N. Estas plantas apresentaram aumento de biomassa e rendimento de grãos, assim como aumento no teor de $\mathrm{N}$ total e metabólitos primordiais, como a glutamina, glutamato e asparagina. Em cevada, a superexpressão do gene AlaAT (HvAlaAT) também resultou na melhoria da EUN em relação às plantas controle, em condição de limitação de N (MCALLISTER et al., 2016).

Com base na similaridade dos mecanismos responsáveis pela maior EUN apresentada por plantas com superexpressão da AlaAT, é possível hipotetizar que plantas geneticamente modificadas para a expressão de gene que codifica a enzima chave na biossíntese do aminoácido prolina (PRO) ( $\Delta^{1}$-pirrolina-5carboxilato sintetase- P5CS) poderiam apresentar fenótipos com melhor EUN. Assim como a AlaAT, a enzima P5CS também está envolvida no metabolismo do N. Embora as enzimas AlaAT e P5CS utilizem diferentes substratos para as suas reações subsequentes, é plausível presumir que as respostas em relação à EUN possam ser semelhantes. Isso porque, em primeiro lugar, ambas utilizam substratos que são intermediários tanto do metabolismo do carbono quanto do nitrogênio, isto é, 2-oxoglutarato, aspartato e glutamato. Em segundo lugar, estas enzimas exercem um impacto direto nas concentrações de glutamato e 2-oxoglutarato nas células, consequentemente afetando o metabolismo de $\mathrm{N}$ na planta (MCALLISTER et al., 2016). Assim, a manipulação genética destes genes pode se constituir em uma opção viável para alterar o equilíbrio bioquímico entre o metabolismo do nitrogênio e do carbono, visando a obtenção de plantas com maior EUN (GOOD; BEATTY, 2011).

Este trabalho objetivou avaliar plantas transgênicas de tabaco (Nicotiana tabacum L.) super-expressando 0 gene mutante VaP5CSF129A que codifica a enzima P5CS (proveniente de Vigna unguiculata L.) sob o controle do promotor constitutivo CaMV 35S, quanto ao seu potencial para aumentar a eficiência do uso de N. 


\section{MATERIAL E MÉTODOS}

$O$ experimento foi conduzido em arranjo inteiramente casualizado, no esquema fatorial $2 \times 5$, formado por dois genótipos, sendo um evento transformado (35S::VaP5CSF129A) e o controle não transformado, e cinco doses de $\mathrm{N}$, na forma de nitrato de amônio $\left(\mathrm{NO}_{3} \mathrm{NH}_{4}\right)(32 \%$ de $\mathrm{N}): 12,5 ; 25 ; 50,100$ e $200 \mathrm{mg} \mathrm{dm}^{-3}$, equivalente a $25,50,100,200$ e $400 \mathrm{~kg} \mathrm{ha}^{-1}$ de N, respectivamente, totalizando 10 tratamentos com 4 repetições em cada tratamento.

As plantas transgênicas de tabaco (Nicotiana tabacum L.) cV. Petit Havana SR1 foram obtidas através da transformação mediada por Agrobacterium tumefaciens estirpe EHA105 (BORGO et al., 2015). O vetor binário usado foi o plasmídeo pBI121-P5CSF129A contendo o gene VaP5CSF129A sob controle do promotor constitutivo CaMV 35S (ZHANG et al., 1995). O evento selecionado para o experimento foi o $35 \mathrm{~S}$ (1), que em estudos prévios mostrou possuir somente uma inserção do transgene e elevada concentração de prolina (BORGO et al., 2015).

Para obter as plantas usadas no experimento, sementes homozigotas da geração T2 do evento selecionado e do controle não transgênico foram desinfetadas com álcool $70 \%$, $\mathrm{NaCl} 2,5 \%$ e água destilada autoclavada. Em seguida foram germinadas in vitro em placas de Petri contendo $25 \mathrm{~mL}$ de meio de cultura constituído de sais do meio MS (pH 5,7) (MURASHIGE; SKOOG, 1962) com concentração reduzida pela metade, suplementado com $5 \mathrm{~g} \mathrm{~L}^{-1}$ de sacarose e solidificado com $10 \mathrm{~g} \mathrm{~L}^{-1}$ de ágar. As sementes foram incubadas por sete dias no escuro e depois colocadas sob a luz. Aproximadamente 20 dias após a semeadura, as plântulas foram repicadas para frascos de vidro contendo $50 \mathrm{~mL}$ de meio de cultura $\mathrm{MS}$, onde permaneceram em câmara de cultivo por aproximadamente 70 dias (período de crescimento). Ao atingir aproximadamente $10 \mathrm{~cm}$ de altura, as plantas in vitro foram transferidas para a aclimatização em casa de vegetação com controle de temperatura ( 23 a 25 으). Para isso, foram utilizados copos plásticos com capacidade de $500 \mathrm{~mL}$, preenchidos com substrato comercial umedecido com solução do meio $\mathrm{MS}$, os quais foram cobertos para criar um microclima adequado para aclimatização, realizando a abertura gradativa da tampa de cobertura por 10 dias.

Em seguida, as plantas foram transferidas para vasos de $10 \mathrm{dm}^{3}$. O solo utilizado para o preenchimento dos vasos foi classificado como um argissolo vermelho distroférrico com teores de argila variando entre $10-12 \%$ no horizonte $A$ (arenoso tipo 1 ). O solo foi preparado com correção de $\mathrm{pH}$ e nutrientes de acordo com a análise química realizada através da metodologia descrita por Raij et al. (2001) (Tabela 1) e com a necessidade da cultura do tabaco, segundo Maia e Raij (1997). Ambos os procedimentos seguiram o princípio de equilibrar a fertilidade do solo para que a deficiência de outro nutriente não limitasse o desenvolvimento das plantas, mascarando os resultados esperados em função do nível de N. Assim, o solo foi pesado, peneirado e a calagem foi realizada com calcário dolomítico (PRNT 85) 20 dias antes da adubação. Para a adubação de base foram adicionados fertilizantes minerais nas quantidades de $10 \mathrm{~g}$ de superfosfato triplo ( $41 \%$ $\left.\mathrm{P}_{2} \mathrm{O}_{5}\right) ; 3,2 \mathrm{~g}$ de cloreto de potássio $\left(58 \% \mathrm{~K}_{2} \mathrm{O}\right)$; $0,08 \mathrm{~g}$ de ácido bórico (17\% B); $0,055 \mathrm{~g}$ de sulfato de cobre $(25 \% \mathrm{Cu}) ; 0,06 \mathrm{~g}$ de sulfato de manganês (26\% Mn); 0,033 g de molibdato de sódio (39\% Mo); $0,085 \mathrm{~g}$ de sulfato de zinco ( $20 \% \mathrm{Zn}$ ) e $1,8 \mathrm{~g}$ de sulfurgran $(90 \%$ S) para cada vaso. A incorporação do nitrogênio foi realizada em dose única, juntamente com os demais nutrientes, no dia anterior ao transplante das mudas para os vasos. Os tratamentos foram compostos por cinco doses de $\mathrm{N}$, aplicado na forma de nitrato de amônio $\left(\mathrm{NO}_{3} \mathrm{NH}_{4}\right)(32 \% \mathrm{~N})$, nas quantidades acima descritas. 
Tabela 1. Característica química do solo utilizado no experimento.

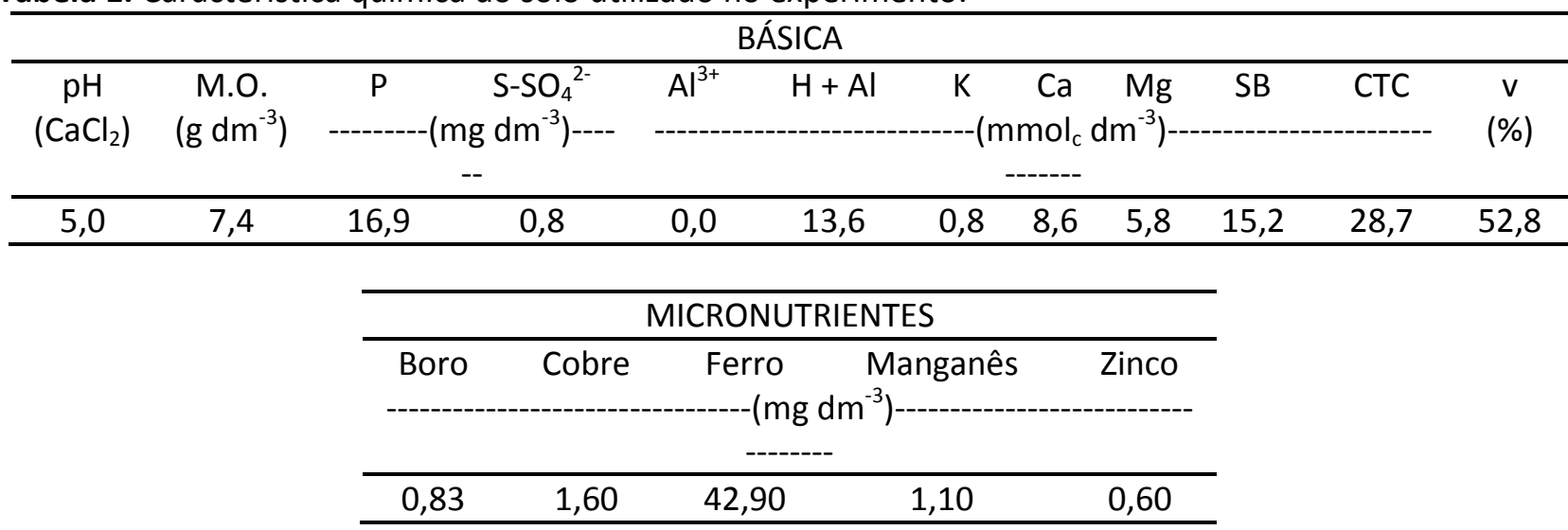

Durante todo o período de cultivo, o solo foi mantido na capacidade de campo, determinada pelo método gravimétrico. Os vasos foram pesados e em seguida saturados com água. Após a drenagem do excesso de água por um período de 24 horas, os vasos foram novamente pesados com o solo úmido (= peso na capacidade de campo). Durante o período experimental os vasos eram pesados e irrigados manualmente para a reposição da água evapotranspirada.

A coleta das folhas e raízes para as avaliações foi realizada aos 30 dias após o transplante para os vasos, as quais foram armazenadas em sacos plásticos em ultrafreezer a -80 ㅇ $\mathrm{C}$ para as análises posteriores. Para a padronização da coleta do material destinado à análise do teor de prolina, elegeu-se a quinta folha totalmente expandida de cada planta. $O$ restante da parte aérea e das raízes foi acondicionado separadamente em sacos de papel $\mathrm{Kraft}^{\circledR}$ para secagem em estufa com circulação forçada de ar (65으), até obtenção do peso constante.

Para avaliar o efeito do $\mathrm{N}$ no crescimento das plantas, foram mensuradas a altura da planta $(\mathrm{cm})$ do colo até a inserção da última inflorescência, o número de folhas totalmente expandidas em cada planta e as massas secas $(\mathrm{g})$ de parte aérea $\left(\mathrm{MS}_{\mathrm{PA}_{\mathrm{A}}}\right)$, raízes $\left(\mathrm{MS}_{\mathrm{R}}\right)$ e total $\left(\mathrm{MS}_{\mathrm{T}}\right)$.

O teor de prolina foi determinado nas folhas e nas raízes de acordo com a metodologia descrita por Bates (1973). O sobrenadante foi utilizado para a leitura em espectrofotômetro a $520 \mathrm{~nm}$ e as absorbâncias comparadas à curvapadrão de prolina $\left(0\right.$ a $\left.80 \mu \mathrm{g} \mathrm{mL}^{-1}\right)$. A análise foi realizada em triplicata e os resultados foram expressos em $\mu \mathrm{mol} \mathrm{g} \mathrm{MF}^{-1}$, obtidos a partir da fórmula: Teor de prolina livre $=\{[(\mu \mathrm{g}$ prolina $\times \mathrm{mL}$ de tolueno) / 115,5 $\mathrm{\mu g} \mathrm{\mu mol}^{-1}$ ] / (gramas de amostra / 6)\}.

$\mathrm{O}$ teor de $\mathrm{N}$ total foi determinado nas folhas e nas raízes, segundo o método de digestão úmida com ácido sulfúrico em bloco digestor, descrito por Malavolta et al. (1997). O teor de $\mathrm{N}$ total, expresso em $\mathrm{g} \mathrm{kg}^{-1}$ de $\mathrm{MS}$, foi determinado pela equação: Teor de nitrogênio total $=[(\mathrm{Va}-\mathrm{Vb}) \times 0,02 \times 14 \times 10]$.

Onde: $\mathrm{Va}=$ volume da solução de $\mathrm{H}_{2} \mathrm{SO}_{4}$ gasto na titulação da amostra $(\mathrm{mL}) ; \mathrm{Vb}=$ volume da solução de $\mathrm{H}_{2} \mathrm{SO}_{4}$ gasto na titulação do branco $(\mathrm{mL}) ; 0,02=$ fator de correção para o $\mathrm{H}_{2} \mathrm{SO}_{4} ; 14=$ equivalente à massa atômica do $\mathrm{N}$ e $10=$ fator de conversão em $\mathrm{g} \mathrm{kg}^{-1}$.

Com base no teor de $\mathrm{N}$ total, foi calculado o teor de proteína total nas folhas, expresso em porcentagem, conforme a equação: Proteína total $=[(\mathrm{NT} / 10) \times 6,25]$.

Onde: NT = teor de nitrogênio total $(\mathrm{g}$ $\mathrm{kg} \mathrm{MS}^{-1}$ ); $10=$ fator de conversão em \% e 6,25 = fator de conversão geral do $\mathrm{N}$ em proteína.

Neste estudo, foi calculada a eficiência nutricional das plantas em relação ao $\mathrm{N}$ disponível, segundo Good et al. (2004), utilizando as equações: eficiência de absorção do nitrogênio (EAbs) = teor de $\mathrm{N}$ na planta ( $\mathrm{N}$ por planta) / $\mathrm{N}$ fornecido na adubação ( $\mathrm{N}$ por vaso); eficiência de utilização do nitrogênio na folha (EUtil) = massa seca da folha (g) / teor de $\mathrm{N}$ na planta (g) e Eficiência de uso do nitrogênio (EUN) = EAbs $x$ EUtil.

Os dados obtidos nas avaliações foram submetidos à análise de variância e as médias foram comparadas entre si pelo teste de Tukey, a $5 \%$ de probabilidade.

\section{RESULTADOS E DISCUSSÃO}

Para todas as variáveis biométricas a análise de variância foi significativa com interação 
entre genótipos e doses (Tabela 2), exceto o número de folhas.

Tabela 2. Resumo da análise de variância para altura da planta (AP), número de folhas (NF), massa seca da parte aérea $\left(M_{P_{A}}\right)$, massa seca da raiz $\left(M S_{R}\right)$, massa seca total $\left(M S_{T}\right)$ e razão parte aérea/raiz (PA/R), provenientes de plantas de tabaco transgênico com alto acúmulo de prolina e plantas controle em função das doses de nitrogênio.

\begin{tabular}{|c|c|c|c|c|c|c|}
\hline \multirow[b]{2}{*}{$\mathrm{FV}$} & \multicolumn{3}{|c|}{ AP } & $\mathrm{MS}_{\mathrm{PA}}$ & $\mathrm{MS}_{\mathrm{R}}$ & $\mathrm{MS}_{\mathrm{T}}$ \\
\hline & GL & $(\mathrm{cm})$ & NF & ------------ & -(gramas) & - \\
\hline Genótipo & 1 & $35,49 * *$ & $35,24 * *$ & $265,33 * *$ & $50,99 * *$ & $343,41 * *$ \\
\hline Dose & 4 & $60,80 * *$ & $50,78 * *$ & $142,62 * *$ & $22,79 * *$ & $182,66 * *$ \\
\hline Genótipo x Dose & 4 & $7,66 * *$ & $0,98 \mathrm{~ns}$ & $10,50 * *$ & $6,43 * *$ & $13,56 * *$ \\
\hline Tratamentos & 9 & $34,37 * *$ & $26,92 * *$ & $97,53 * *$ & $18,65 * *$ & $125,37 * *$ \\
\hline CV \% & & 3,55 & 11,90 & 3,02 & 4,38 & 2,30 \\
\hline
\end{tabular}

** significativo ao nível de $1 \%$ de probabilidade $(p<0,01)$

ns não significativo $(p \geq 0,05)$

Na comparação entre genótipos, as plantas-controle apresentaram maior altura que as transgênicas, exceto na dose de $25 \mathrm{~kg} \mathrm{ha}^{-1}$ de $\mathrm{N}$. $\mathrm{O}$ incremento de $\mathrm{N}$ foi positivo para ambos os genótipos, os quais responderam com aumentos em altura (Figura 1A). As plantas-controle apresentaram maior massa seca da parte aérea em relação às plantas transgênicas em todas as doses de $\mathrm{N}$ avaliadas (Figura 1B), sendo o maior incremento nas doses intermediárias e alta (100, 200 e $400 \mathrm{~kg} \mathrm{ha}^{-1}$ de N). Para a massa seca da raiz (Figura 1C), não houve diferença entre os genótipos paras as doses 25 e $50 \mathrm{~kg} \mathrm{ha}^{-1}$ de $\mathrm{N}$. Porém, para as demais doses, verificou-se que as plantas transgênicas apresentaram menor massa seca de raízes em comparação às controle. Na comparação entre doses de $\mathrm{N}$ dentro de cada genótipo, as de 200 e $400 \mathrm{~kg} \mathrm{ha}^{-1}$ proporcionaram aumento na massa seca de raízes das plantascontrole, enquanto que, para as transgênicas não houve diferença significativa entre as mesmas.

A Figura 1D destaca que houve maior massa nas plantas-controle em relação às transgênicas em todas as doses de $\mathrm{N}$ testadas, como consequência das maiores massas de parte aérea e raiz. Avaliando-se as doses de $\mathrm{N}$ dentro de cada genótipo, tanto as plantas-controle como as transgênicas apresentaram aumento na produção de biomassa total em resposta aos incrementos na dose de $\mathrm{N}$. Porém, observa-se que a o crescimento das plantas controle se estabilizou a partir da dose de $200 \mathrm{~kg} \mathrm{ha}^{-1}$ e nas plantas transgênicas a partir da dose de $100 \mathrm{Kg}$ $\mathrm{ha}^{-1}$ (Figura 1A). 
Figura 1. Efeito da interação entre doses de nitrogênio $\left(1=25,2=50,3=100,4=200 \mathrm{Kg}\right.$ e $\left.5=400 \mathrm{~kg} \mathrm{~N} \mathrm{ha}^{-1}\right)$ e genótipos das plantas de tabaco (controle e transgênico) para altura, massa seca de parte aérea (folhas + hastes + flores), massa seca da raiz e massa seca total da planta.

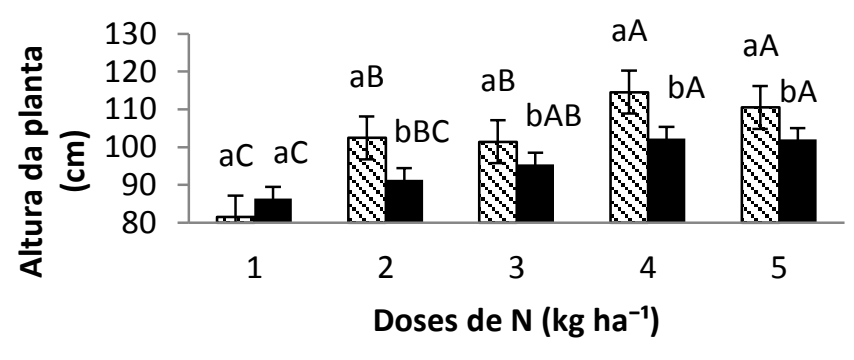

QControle $\mathbf{T}$ Transgênica

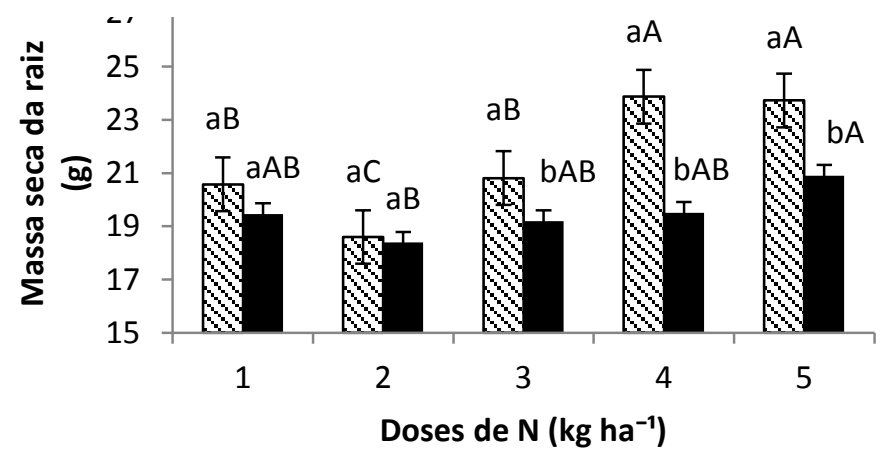

๑Controle Transgênica

(A)
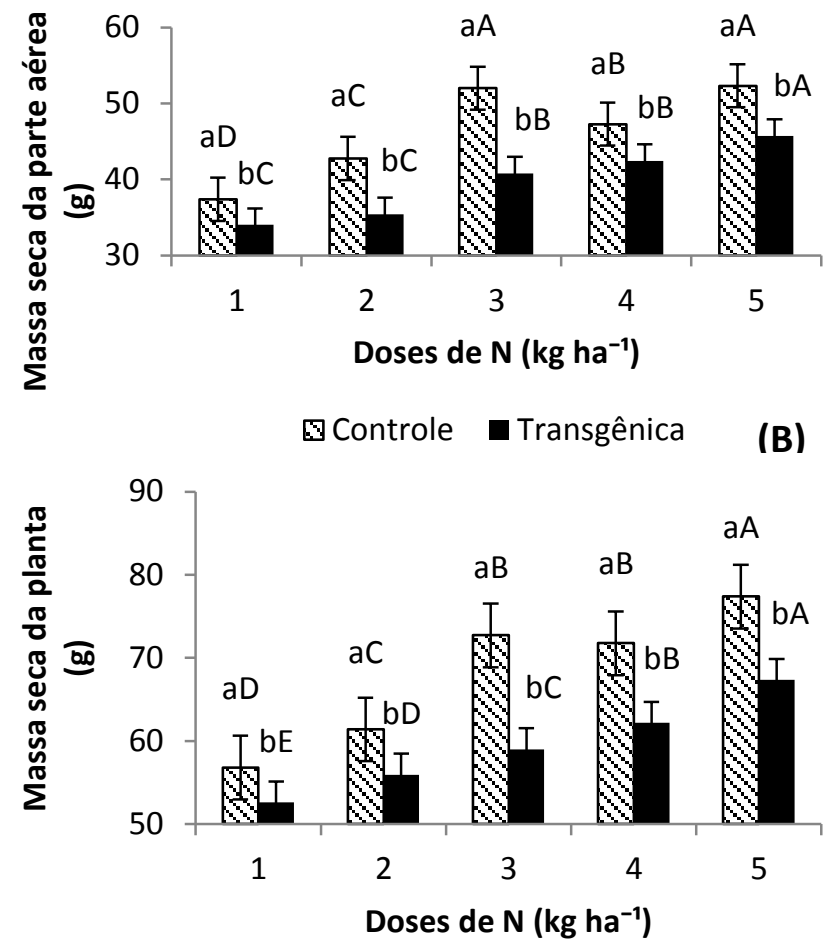

QControle

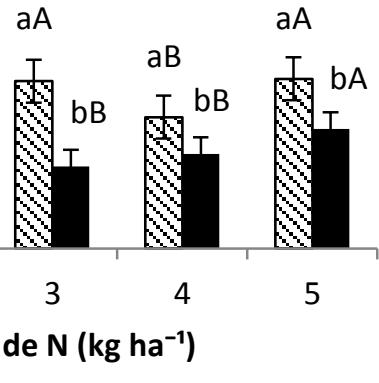

(B)

(D)

Letras minúsculas representam diferença significativa entre os genótipos dentro de cada dose de $\mathrm{N}$ e maiúsculas entre as doses de $\mathrm{N}$ em cada genótipo. Foi aplicado o Teste de Tukey ao nível de 5\% de probabilidade.

As plantas transgênicas apresentaram maior número de folhas por planta em relação às plantas controle, e o número folhas foi maior nas doses intermediárias de N (100 e $\left.200 \mathrm{~kg} \mathrm{ha}^{-1}\right)$ para ambos os genótipos (Tabela 3).

Tabela 3. Efeito de doses de nitrogênio e dos genótipos das plantas de tabaco (controle e transgênico) para o número de folhas por planta.

\begin{tabular}{ccc}
\hline Genótipo & \multicolumn{2}{c}{ № folhas } \\
\hline $\begin{array}{c}\text { Transgênica } \\
\text { Controle }\end{array}$ & 26,94 & a \\
Dose de N & & b \\
$\left(\right.$ kg ha $\left.^{-1}\right)$ & & \\
\hline 25 & 14,41 & $\mathrm{c}$ \\
50 & 21,16 & $\mathrm{~b}$ \\
100 & 31,94 & $\mathrm{a}$ \\
200 & 30,84 & $\mathrm{a}$ \\
400 & 22,81 & $\mathrm{~b}$
\end{tabular}

Médias seguidas pela mesma letra na coluna não diferem entre si pelo Teste de Tukey ao nível de $5 \%$ de probabilidade.

Não houve efeito significativo quanto aos teores de prolina na folha e na raiz considerando a interação entre os genótipos e as doses de $\mathrm{N}$ (Tabela 4). Como esperado, as plantas transgênicas apresentaram maior acúmulo de prolina na folha em relação às plantas-controle, enquanto o acúmulo de prolina na raiz não diferiu entre os genótipos. O maior acúmulo de 
prolina nas folhas e raízes foi obtido com a dose de $400 \mathrm{~kg} \mathrm{ha}^{-1}$ de N (Tabela 5).

Tabela 4. Resumo da análise de variância para os resultados de prolina livre da folha (PRO folha), prolina livre da raiz (PRO raiz) e proteína total da folha (PT), provenientes de genótipos de plantas de tabaco (controle e transgênico) em função de doses de nitrogênio.

\begin{tabular}{|c|c|c|c|c|}
\hline & & PRO folha & PRO raiz & \multirow{2}{*}{$\begin{array}{c}\mathrm{PT} \\
(\%)\end{array}$} \\
\hline FV & $\mathrm{GL}$ & \multicolumn{2}{|c|}{-------( mol gMF $\left.^{-1}\right)------$} & \\
\hline Genótipo & 1 & $15,36 * *$ & $1,11 \mathrm{~ns}$ & $176,11 * *$ \\
\hline Dose & 4 & $123,91 * *$ & $38,74 * *$ & $1493,20 * *$ \\
\hline Genótipo x Dose & 4 & $1,76 \mathrm{~ns}$ & $1,95 \mathrm{~ns}$ & $45,19 * *$ \\
\hline Tratamentos & 9 & $57,56 * *$ & $18,21 * *$ & $703,29 * *$ \\
\hline CV \% & & 29,43 & 9,05 & 3,83 \\
\hline
\end{tabular}

** significativo ao nível de $1 \%$ de probabilidade $(p<0,01)$

ns não significativo $(p \geq 0,05)$

Tabela 5. Efeito de doses de nitrogênio e dos genótipos das plantas de tabaco (controle e transgênico) para a prolina livre na folha e na raiz $\left(\mu \mathrm{mol} \mathrm{g} \mathrm{MF}^{-1}\right)$.

\begin{tabular}{crrrr}
\hline Genótipo & \multicolumn{2}{c}{ PRO folha } & \multicolumn{2}{c}{ PRO raiz } \\
\hline Transgênica & 24,65 & a & 18,40 & a \\
Controle & 17,04 & b & 17,85 & a \\
\hline $\left.\begin{array}{c}\text { Doses de N } \\
\text { (kg ha }\end{array}{ }^{-1}\right)$ & & & & \\
\hline 25 & 4,88 & $\mathrm{c}$ & 16,08 & b \\
50 & 5,92 & c & 16,19 & b \\
100 & 9,74 & c & 16,09 & b \\
200 & 21,24 & b & 17,85 & b \\
400 & 62,45 & a & 24,44 & a \\
\hline
\end{tabular}

Médias seguidas pela mesma letra na coluna não diferem entre si pelo Teste de Tukey ao nível de $5 \%$ de probabilidade.

Em relação ao teor foliar de proteína total (Figura 2), com exceção da dose de $25 \mathrm{~kg}$ ha' 1 de $\mathrm{N}$, as plantas transgênicas apresentam maiores teores em relação às plantas controle em função do aumento gradativo no fornecimento de $\mathrm{N}$ no solo. 
Figura 2. Efeito da interação entre as doses de nitrogênio $(1=25,2=50,3=100,4=200 \mathrm{Kg}$ e $5=400 \mathrm{~kg} \mathrm{~N}$ ha $\left.{ }^{1}\right)$ e os genótipos das plantas de tabaco (controle e transgênico) sobre o teor de proteína total nas folhas.

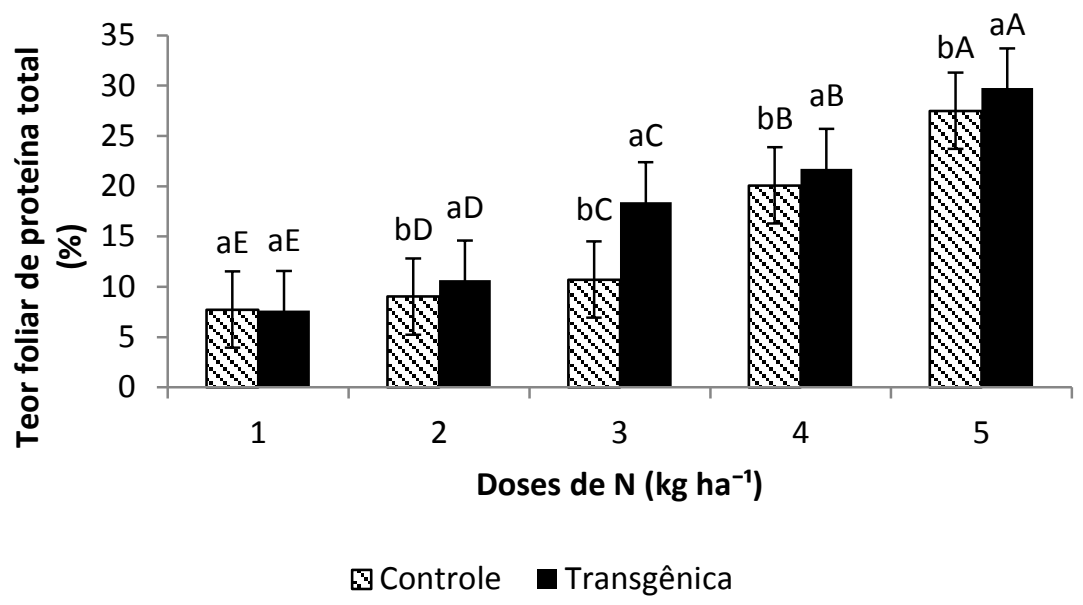

Letras minúsculas representam diferença significativa entre os genótipos dentro de cada dose de $\mathrm{N}$ e maiúsculas entre as doses de $\mathrm{N}$ em cada genótipo. Foi aplicado o Teste de Tukey ao nível de $5 \%$ de probabilidade.

Houve efeito significativo isolado para os fatores genótipo e doses de $\mathrm{N}$ em relação aos teores de $\mathrm{N}$ nas folhas, raízes e planta (Tabela 6). As plantas transgênicas apresentaram valores inferiores de $\mathrm{N}$ na folha, raiz e planta inteira quando comparadas às plantas-controle. $\mathrm{Na}$ comparação entre as doses de $\mathrm{N}$ dentro de cada genótipo, observa-se que tanto as plantascontrole como as transgênicas responderam positivamente ao aumento da quantidade de $\mathrm{N}$ fornecida ao solo (Tabela 7).

Tabela 6. Resumo da análise de variância para o teor de nitrogênio total na folha ( $N$ folha), teor de nitrogênio total na raiz ( $\mathrm{N}$ raiz) e teor de nitrogênio total na planta ( $\mathrm{N}$ planta), provenientes de genótipos de plantas de tabaco (controle e transgênico) em função de doses de nitrogênio.

\begin{tabular}{|c|c|c|c|c|}
\hline FV & GI & $\mathrm{N}_{\mathrm{F}}$ & $\mathrm{N}_{\mathrm{R}}$ & $\mathrm{N}_{\mathrm{p}}$ \\
\hline FV & GL & - & -- (g kg) & \\
\hline Genótipo (G) & 1 & $13,74 * *$ & $25,47^{* *}$ & $37,16 * *$ \\
\hline Dose (D) & 4 & $58,66 * *$ & $35,13 * *$ & $93,63 * *$ \\
\hline$G \times D$ & 4 & $1,72^{\mathrm{ns}}$ & $0,60^{\mathrm{ns}}$ & $2,17^{\mathrm{ns}}$ \\
\hline Tratamentos & 9 & $28,36 * *$ & $18,71 * *$ & $46,71^{* *}$ \\
\hline CV\% & & 26,97 & 19,18 & 16,12 \\
\hline
\end{tabular}

** significativo ao nível de $1 \%$ de probabilidade $(p<0,01)$

ns não significativo $(p \geq 0,05)$ 
Tabela 7. Efeitos isolados das doses de nitrogênio e dos genótipos das plantas de tabaco (controle e transgênico) para os teores de nitrogênio na folha, na raiz e na planta (g kg MS ${ }^{-1}$ ).

\begin{tabular}{|c|c|c|c|c|c|}
\hline Genótipo & \multicolumn{2}{|c|}{$\mathrm{N}$ folha } & \multicolumn{2}{|l|}{$\mathrm{N}$ raiz } & \multirow{2}{*}{$\begin{array}{c}\mathrm{N} \text { planta } \\
0,6251 \mathrm{~b}\end{array}$} \\
\hline Transgênica & 0,2863 & $b$ & 0,3388 & $b$ & \\
\hline Controle & 0,3806 & $\mathrm{a}$ & 0,4463 & $a$ & $0,8269 a$ \\
\hline \multicolumn{6}{|l|}{$\begin{array}{c}\text { Doses de N } \\
\left(\mathrm{kg} \mathrm{ha}^{-1}\right)\end{array}$} \\
\hline 25 & 0,1254 & $d$ & 0,2547 & c & $0,3801 \mathrm{~d}$ \\
\hline 50 & 0,1832 & $\mathrm{~cd}$ & 0,2781 & c & $0,4613 \mathrm{~d}$ \\
\hline 100 & 0,2596 & c & 0,3785 & $b$ & $0,6382 c$ \\
\hline 200 & 0,4372 & $b$ & 0,4486 & $b$ & $0,8859 b$ \\
\hline 400 & 0,6616 & $\mathrm{a}$ & 0,6029 & $\mathrm{a}$ & $1,2645 \mathrm{a}$ \\
\hline
\end{tabular}

Médias seguidas pela mesma letra na coluna não diferem entre si pelo Teste de Tukey ao nível de $5 \%$ de probabilidade.

Os resultados de eficiência em relação ao aproveitamento do $\mathrm{N}$ disponibilizado, como as eficiências de absorção (EAbs) e de uso do nitrogênio (EUN), indicaram apenas efeito significativo isolado para os genótipos. A exceção foi observada para a EUtil (Tabela 8).

Tabela 8. Resumo da análise de variância para os resultados de eficiências de aproveitamento do nitrogênio disponibilizado, como a eficiência de absorção (EAbs), eficiência de utilização na folha (EUtil) e eficiência de uso do nitrogênio (EUN), em genótipos de plantas de tabaco (controle e transgênico) em função de doses de nitrogênio.

\begin{tabular}{lcrrr}
\hline \multicolumn{1}{c}{ FV } & GL & \multicolumn{1}{c}{ EAbs } & \multicolumn{1}{c}{ EUtil } & \multicolumn{1}{c}{ EUN } \\
\hline Genótipo & 1 & $35,19^{* *}$ & $2,76 \mathrm{~ns}$ & $11,24 * *$ \\
Dose & 4 & $176,74^{* *}$ & $13,81^{* *}$ & $53,19^{* *}$ \\
Genótipo x Dose & 4 & $1,36 \mathrm{~ns}$ & $2,54 \mathrm{~ns}$ & $1,27 \mathrm{~ns}$ \\
Tratamentos & 9 & $83,06^{* *}$ & $7,57^{* *}$ & $25,45^{* *}$ \\
\hline \multicolumn{1}{c}{ CV\% } & & 14,83 & 25,31 & 34,65 \\
\hline
\end{tabular}

** significativo ao nível de $1 \%$ de probabilidade $(p<0,01)$

ns não significativo $(p \geq 0,05)$

As plantas transgênicas foram menos eficientes na absorção do $\mathrm{N}$ disponível no solo em relação às controle, ocorrendo diminuição significativa da EAbs conforme aumentou-se a dose de $\mathrm{N}$ aplicada (Tabela 9). Não houve diferença entre os genótipos quanto à EUtil, ou seja, na sua capacidade em assimilar o $\mathrm{N}$ absorvido para a produção de massa foliar. $\mathrm{Na}$ comparação entre as doses, ocorreu diminuição significativa da EUtil somente na maior dose de N. Em relação à EUN, as plantas-controle se destacaram positivamente em comparação às plantas transgênicas e, para ambos os genótipos, quando analisado o efeito isolado das doses de $\mathrm{N}$, houve menor EUN com o aumento da dose de $\mathrm{N}$. 
Tabela 9. Efeito das doses de nitrogênio e dos genótipos das plantas de tabaco (controle e transgênico) em relação às eficiências de absorção de nitrogênio (EAbs), utilização de nitrogênio (EUtil) e eficiência de uso do nitrogênio (EUN).

\begin{tabular}{|c|c|c|c|c|}
\hline Genótipo & EAbs & & EUtil & EUN \\
\hline Transgênica & 1,34 & b & $18,47 \quad a$ & $28,26 \quad b$ \\
\hline Controle & 1,72 & a & $20,81 \quad a$ & $39,37 \quad a$ \\
\hline \multicolumn{5}{|l|}{$\begin{array}{c}\text { Dose de N } \\
\left(\mathrm{kg} \mathrm{ha}^{-1}\right)\end{array}$} \\
\hline 25 & 3,04 & $a$ & $24,22 \quad a$ & $73,51 \quad a$ \\
\hline 50 & 1,84 & $b$ & $26,30 \quad a$ & $48,00 \quad b$ \\
\hline 100 & 1,27 & c & $19,98 \mathrm{ab}$ & 26,16 \\
\hline 200 & 0,88 & $d$ & 15,29 bc & $13,69 \mathrm{~cd}$ \\
\hline 400 & 0,63 & $d$ & $12,41 \quad \mathrm{c}$ & $7,72 \mathrm{~d}$ \\
\hline
\end{tabular}

Médias seguidas pela mesma letra na coluna não diferem entre si pelo Teste de Tukey ao nível de $5 \%$ de probabilidade.

De acordo com os dados apresentados, as plantas-controle apresentaram valores superiores em altura, $M_{P A}$ e $M_{R}$, e consequentemente, $\mathrm{MS}_{\mathrm{p}}$ produzida (Figura 1). Enquanto as plantas-controle utilizaram o $\mathrm{C}$ assimilado para a produção de massa, as transgênicas desviaram compostos carbônicos para a produção e acúmulo de prolina, em detrimento ao seu crescimento. Assim como a AlaAT, a enzima P5CS utiliza no seu mecanismo de biossíntese importantes componentes do metabolismo de nitrogênio e de carbono, os quais por sua vez são diretamente ligados ao ciclo GS-GOGAT, atuante no metabolismo primário de $\mathrm{N}$ na planta. A disponibilidade de 2-oxoglutarato (2-OG) pode ter sido um fator limitante para o crescimento dessas plantas, desde que o mesmo é necessário tanto para o funcionamento do sistema GS-GOGAT como também para a produção de importantes compostos orgânicos. Para o funcionamento do ciclo GS-GOGAT são utilizados o 2-oxoglutarato (importante substrato proveniente do ciclo do TCA) e o piruvato (substrato envolvido em processos relacionados ao metabolismo do carbono, tais como a glicólise, a gluconeogênese e a fermentação) (LOCK, 2011). Além da sua participação no ciclo GS-GOGAT, o 2OG é um ácido orgânico utilizado como substrato obrigatório para uma série de reações oxidativas catalisadas por enzimas dioxigenases dependentes de 2-OG. Essas reações ocorrem em compartimentos celulares distintos e são importantes para o metabolismo de diferentes compostos secundários na planta, tais como glucosinolatos, alcaloides e flavonoides (ARAÚJO et al., 2014).
Dessa maneira, as plantas transgênicas com super-expressão da enzima P5CS podem ter utilizado atipicamente os esqueletos de carbono para produzir altos níveis de prolina, ao invés de seu uso para acumular biomassa. Portanto, nas plantas transgênicas, a utilização concomitante do 2-OG para uma alta produção de prolina e para a síntese de compostos orgânicos pode gerar competição por esqueletos de carbono que seriam utilizados para o crescimento. Além disso, podemos adicionalmente citar o fato de que o 2OG é um regulador direto de diferentes enzimas associadas ao fluxo de açúcar e/ou ácidos orgânicos (HODGES, 2002) e pode, portanto, regular as taxas de respiração em plantas superiores (ARAÚJO et al., 2014). Apesar de produzir menos biomassa, as plantas transgênicas apresentaram maior número de folhas (Tabela 3), o que resultou em entrenós mais curtos em comparação com as plantascontrole (dados não apresentados). A provável causa para a diminuição do crescimento das plantas transgênicas é a queda no nível do ácido giberélico ativo $\mathrm{GA}_{1}$, que atua no alongamento dos entre nós (RADEMACHER, 2000), pelo desvio de 2-OG para a produção de prolina. De acordo com Araújo et al. (2014), o 2-OG e as enzimas dioxigenases dependentes de 2-OG também exercem função chave no metabolismo das giberelinas, sendo que parte da biossíntese deste regulador de crescimento é controlada pela quantidade de 2-OG na planta. Portanto, a disponibilidade temporal e espacial de 2-OG nas plantas com alta produção de prolina merecem estudos mais aprofundados.

De modo geral, tanto as plantas transgênicas quanto as controle responderam de 
forma positiva ao aumento das doses de $\mathrm{N}$ no solo (Figura 1). Porém, o aumento das doses de $\mathrm{N}$ nas plantas transgênicas se reverteu em maiores teores de compostos nitrogenados nas folhas, na forma de prolina e proteínas (Tabela 5; Figura 3).

As plantas transgênicas apresentaram menores teores de $\mathrm{N}$ nas folhas e nas raízes (Tabela 6). Provavelmente, a absorção reduzida deste elemento esteve correlacionada com a menor massa seca radicular quando comparadas com as plantas-controle. Alterações na arquitetura e no crescimento das raízes podem beneficiar ou prejudicar a absorção de nutrientes pelas plantas (HERDER et al., 2010). Consequentemente, tais resultados se refletiram em menor EAbs nas plantas transgênicas (Tabela 9). A diminuição da EAbs, com o aumento da dose de $\mathrm{N}$, também pode estar relacionada à atividade dos sistemas de alta e baixa afinidade de absorção de $\mathrm{N}$ em ambos os genótipos. Em condições de restrição de $\mathrm{N}$ pode haver aumento da atividade dos transportadores de alta afinidade e, consequentemente, aumento na velocidade de absorção do elemento (HOWITT et al., 1999). Em contrapartida, à medida que a concentração de $\mathrm{N}$ aumentou no solo, pode ter ocorrido ativação dos transportadores de baixa afinidade localizados nas raízes, ocorrendo, portanto, redução da velocidade de absorção e acúmulo de $\mathrm{N}$ no período de desenvolvimento das plantas.

A EUtil, a qual reflete a capacidade da planta em assimilar o $\mathrm{N}$ absorvido para a produção de massa seca no órgão de interesse (no caso do tabaco, as folhas), não foi diferente entre os genótipos controle e transgênico. Embora as plantas transgênicas tenham apresentado maior número de folhas em relação às controle, suas folhas provavelmente apresentaram menor tamanho e/ou espessura, refletindo-se em menor massa seca. De acordo com Shewry (2007), fisiologicamente, a maior EUtil é obtida se a absorção de $\mathrm{N}$ for mantida a um mínimo, já que o $\mathrm{N}$ é necessário para a produção do aparato fotossintético da folha e, em última análise, a fotossíntese também é necessária para suportar a produtividade da cultura.

Uma vez que a EUN é estabelecida pelo produto entre as eficiências de absorção e de utilização de nitrogênio pela planta, a menor EAbs verificada nas plantas transgênicas, fez com que as mesmas apresentassem menor EUN em relação às controle (Tabela 9), ao contrário do que foi observado em plantas super-expressando a enzima AlaAT (GOOD et al., 2007; SHRAWAT et al., 2008). Assim, a expressão constitutiva do gene mutante VaP5CSF129A para biossíntese de prolina não se mostrou uma opção viável para alterar o equilíbrio bioquímico entre os metabolismos de nitrogênio e do carbono, a fim de se produzir uma planta com maior EUN.

Estudos com transgênicos utilizando promotores constitutivos genéricos para conduzir um gene alvo de superexpressão em plantas, tais como o vírus do mosaico da couve flor (CaMV $35 \mathrm{~S}$ ) e o promotor de ubiquitina de milho (UBI-1), apontam uma desvantagem na utilização desses promotores, uma vez que pode ser energeticamente desfavorável para as plantas expressarem o gene em todos os momentos. Adicionalmente, existe a possibilidade de ocorrer um desenvolvimento anormal da planta, uma vez que os níveis de expressão do transgene não são regulados (SHELTON et al., 2002), o que pode ter acontecido nesse estudo. Uma resposta melhor poderia ter sido alcançada com a utilização de promotores induzíveis ao invés de constitutivos. Os promotores induzíveis conduzem somente a expressão do gene quando um estímulo físico, ambiental, biológico ou químico específico é aplicado (FREEMAN et al., 2011). Em outra pesquisa, onde foi utilizado o gene HvAlaAT conduzido pelo promotor CaMV 35S, as plantas de canola (Brassica napus L.) não apresentaram maior EUN. No entanto, quando foi utilizado o promotor btg26 específico de raiz, as plantas geradas apresentaram maior EUN (GOOD et al., 2007).

A superexpressão de um gene em si também pode não ser suficiente para afetar a EUN de uma planta, mas quando combinada com um promotor específico de tecido pode produzir um forte fenótipo em relação à EUN (LOCK, 2011). Desta maneira, o emprego de construções gênicas com promotores órgão/tecido específicos ou induzidos pode provar ser uma opção mais adequada para evitar os efeitos deletérios causados pelo alto acúmulo de prolina devido a super-expressão do gene VaP5CS129A. Isto poderia limitar e controlar a expressão do transgene temporal e espacialmente em tecidos/órgãos, melhorando-se a EAbs e ao mesmo tempo evitando a diminuição da biomassa e, consequentemente, proporcionando maior EUN. 


\section{CONCLUSÃO}

A super-expressão do transgene VaP5CS129A em tabaco sob controle do promotor constitutivo CaMV $35 \mathrm{~S}$ para proporcionar alto acúmulo de prolina não apresentou potencial de utilização direta em sistemas agrícolas. Entretanto, o emprego de construções gênicas com promotores órgão/tecido específicos ou induzidos pode ser uma opção adequada para evitar os efeitos deletérios causados pelo alto acúmulo de prolina.

\section{REFERÊNCIAS}

ABIKO, T.; WAKAYAMA, M.; KAWAKAMI, A.; OBARA, M.; KISAKA, H.; MIWA, T.; AOKI, N.; OHSUGI, R. Changes in nitrogen assimilation, metabolism, and growth in transgenic rice plants expressing a fungal NADP(H)-dependent glutamate dehydrogenase (GDHA). Planta, v.232, p.299-311, 2010. https://doi.org/10.1007/s00425-010-1172-3

ARAÚJO, W. L.; MARTINS, A. O.; FERNIE, A. R.; TOHGE, T. 2-Oxoglutarate: linking TCA cycle function with amino acid, glucosinolate, flavonoid, alkaloid, and gibberellin biosynthesis. Frontiers in Plant Science: Plant Metabolism and Chemodiversity, v.5, p.1-6, out. 2014. https://doi.org/10.3389/fpls.2014.00552

BATES, L. S. Rapid determination of free proline for water stress studies. Plant Soil, v.39, p.205207, ago. 1973.

BORGO, L.; MARUR, C. J.; VIEIRA, L. G. E. Effects of high proline accumulation on chloroplast and mitochondrial ultrastructure and on osmotic adjustment in tobacco plants. Acta Scientiarum Agronomy, v.37, n.2, p.191-199, 2015. https://doi.org/10.4025/actasciagron.v37i2.1909 $\underline{7}$

BRAUER, E. K.; ROCHON, A.; BI, Y. M.; BOZZO, G. G.; ROTHSTEIN, S. J.; SHELP, B. J. Reappraisal of nitrogen use efficiency in rice overexpressing glutamine synthetase. Plant Physiology, v.141, p.361-372, 2011. https://doi.org/10.1111/j.1399$\underline{3054.2011 .01443 . x}$

BREDEMEIER, C.; MUNDSTOCK, C. M. Regulação da absorção e assimilação do nitrogênio nas plantas. Ciência Rural, v.30, n.2, p.365-372, 2000. https://doi.org/10.1590/S0103$\underline{84782000000200029}$
CHICHKOVA, S.; ARELLANO, J.; HERNÁNDEZ, G. Transgenic tobacco plants that overexpress alfalfa NADH-glutamate synthase have higher carbon and nitrogen content. Journal of Experimental Botany, v.52, p.2079-2087, 2001. https://doi.org/10.1093/jexbot/52.364.2079

FREEMAN, J.; SPARKS, C. A.; WEST, J.; SHEWRY, P. R.; JONES, H. D. Temporal and spatial control of transgene expression using a heat-inducible promoter in transgenic wheat. Plant Biotechnology Journal, v.9, n.7, p.788-796, 2011. https://doi.org/10.1111/j.1467-

7652.2011.00588.x

GAUTHIER, P. P.; BLIGNY, R.; GOUT, E.; MAHÉ, A.; NOGUÉS, S.; HODGES, M.; TCHERKEZ, G. G. In folio isotopic tracing demonstrates that nitrogen assimilation into glutamate is mostly independent from current $\mathrm{CO} 2$ assimilation inilluminated leaves of Brassica napus. New Phytologist, v.185, p.988-999, 2010. https://doi.org/10.1111/j.1469-

8137.2009.03130.x

GOLDIN, A. Reassessing the use of loss-onignition for estimating organic matter content in noncalcareous soils. Commun. Soil Science and Plant Analysis, v.18, n.10, p.1111-1116, 1987. https://doi.org/10.1080/00103628709367886

GOOD, A. G.; BEATTY, P. H. Fertilizing Nature: A Tragedy of Excess in the Commons. Plos Biology, v.9, n.8, p.1-9, 2011. https://doi.org/10.1371/journal.pbio.1001124

GOOD, A. G.; JOHNSON, S. J.; PAUW, M.; CARROLL, R. T.; SAVIDOV, N.; VIDMAR, J.; LU, Z.; TAYLOR, G.; STROEHER, V. Engineering nitrogen use efficiency with alanine aminotransferase. Canadian Journal of Botany, v.85, p.252-262, 2007. https://doi.org/10.1139/B07-019

GOOD, A. G.; SHRAWAT, A. K.; MUENCH, D. G. Can less yield more? Is reducing nutrient input into the environment compatible with maintaining crop production? Trends in Plant Science, v.9, n.12, p.597-605, 2004. https://doi.org/10.1016/j.tplants.2004.10.008

HARPER, J. E. Nitrogen metabolism. In: BOOTE, K. J., BENNETT. J. M., SINCLAIR, T. R., et al. Physiology and Determination of Crop Yield, Madison: ASA/CSSA/SSSA, 1994. p.285-302. 
HERDER, G. D.; ISTERDAEL, G. V.; BEECKMAN, T.; SMET, I. D. The roots of a new green revolution. Trends in Plant Science, v.15, n.11, p.600-607, 2010.

https://doi.org/10.1016/j.tplants.2010.08.009

HODGES, M. Enzyme redundancy and the importance of 2-oxoglutarate in plant ammonium assimilation. Journal of Experimental Botany, v.53, p.905-916, 2002. https://doi.org/10.1093/jexbot/53.370.905

HOWITT, C. A.; UDALL, P. K.; VERMAAS, W. F. J. Type $2 \mathrm{NADH}$ dehydrogenases in the cyanobacterium Synechocystis sp. strain PCC 6803 are involved in regulation rather than respiration. Journal of Bacteriology, v.181, n.13, p.3994-4003, 1999.

LAM, H. M.; WONG, P.; CHAN, H. K.; YAM, K. M.; CHEN, L.; CHOW, C. M.; CORUZZI, G. M. Overexpression of the ASN1 gene enhances nitrogen status in seeds of Arabidopsis. Plant Physiology, v.132, p.926-935, 2003. https://doi.org/10.1104/pp.103.020123

LAWLOR, D. W. Carbon and nitrogen assimilation in relation to yield: mechanisms are the key to understanding production systems. Journal Experimental Botany, v.53, p.773-787, 2002. https://doi.org/10.1093//xb/53.370.773

LEA, P. J. Nitrogen Metabolism. In: LEA, P. J.; LEEGOOD, R. C. Plant Biochemistry and Molecular Biology, Chichester: John Wiley and Sons, 1993. cap. 7, p. 155-180.

LIANG, X.; ZHANG, L.; NATARAJAN, S. K.; BECKER, D. F. Proline mechanisms of stress survival. Antioxidants and Redox Signaling, v.19, n.9, p.998-1011, 2013. https://doi.org/10.1089/ars.2012.5074

LOCK, Y. Y. Engineering nitrogen use efficiency in Oryza sativa by the developmental overexpression of barley alanine aminotransferase using a novel rice promoter. 2011. $137 \mathrm{f}$. Dissertation (Master of Science in Plant Biology) University of Alberta, 2011.

MAIA, N. B.; RAIJ, B. V. Fumo. In: RAIJ, B. V. et al. Boletim Técnico 100. 2. ed. São Paulo: Instituto Agronômico / Fundação IAC, 1997. p.103-104.
MALAVOLTA, E.; VITTI, G. C.; OLIVEIRA, S. A. Avaliação do estado nutricional das plantas: princípios e aplicações. Piracicaba: Potafos, 1997.

MCALLISTER, C. H.; BEATTY, P. H.; GOOD, A. G. Engineering nitrogen use efficient crop plants: the current status. Plant Biotechnology Journal, v.10, p.1011-1025, 2012. https://doi.org/10.1111/j.14677652.2012.00700.x

MCALLISTER, C. H.; WOLANSKY, M.; GOOD, A. G. The impact on nitrogen-efficient phenotypes when aspartate aminotransferase is expressed tissue-specifically in Brassica napus. New Negatives in Plant Science, v.3, p.1-9, 2016. https://doi.org/10.1016/j.neps.2016.03.001

MOLINARI, H. B. C.; MARUR, C. J.; FILHO, J. C. B.; KOBAYASHI, A. K.; PILEGGI, M.; JÚNIOR, R. P. L.; PEREIRA, L. F. P.; VIEIRA, L. G. E. Osmotic adjustment in transgenic citrus rootstock Carrizo citrange (Citrus sinensis Osb. $X$ Poncirus trifoliata $\mathrm{L}$. Raf.) over producing proline. Plant Science: an International Journal of Experimental Plant Biology, v.167, n.6, p.1375-1381, 2004. https://doi.org/10.1016/j.plantsci.2004.07.007

MOLL, R. H.; KAMPRATH, E. J.; JACKSON, W. A. Analysis and interpretation of factors which contribute to efficiency of nitrogen utilization. Agronomy Journal, v.74, p.562-64, 1982. https://doi.org/10.2134/agronj1982.0002196200 7400030037x

MUENCH, D. G.; GOOD, A. G. Hypoxically inducible barley alanine aminotransferase: cDNA cloning and expression analysis. Plant Molecular Biology, v.24, p.417-427, 1994. https://doi.org/10.1007/BF00024110

MURASHIGE, T.; SKOOG, F. A revised medium for rapid growth and bio assays with tobacco tissue cultures. Physiologia Plantarum, v.15, p.473-497, 1962. https://doi.org/10.1111/j.13993054.1962.tb08052.x

RADEMACHER, W. Growth retardants: effects on gibberellin biosynthesis and other metabolic pathways. Annual Review of Plant Physiology and Plant Molecular Biology, v.51, n.1, p.501531, 
https://doi.org/10.1146/annurev.arplant.51.1.50 1

RAIJ, B. V.; ANDRADE, J. C.; CANTARELLA, H.; QUAGGIO, J. A. Análise química para avaliação da fertilidade de solos tropicais. Campinas: Instituto Agronômico, 2001. p.285.

RUIZ, J. M.; RIVERO, R. M.; GARCIA, P. C.; BAGHOUR, M.; ROMERO, L. Role of $\mathrm{CaCl}_{2}$ in nitrate assimilation in leaves and roots of tobacco plants (Nicotiana tabacum L). Plant Science: an International Journal of Experimental Plant Biology, v.141, n.2, p.107-115, 1999. https://doi.org/10.1016/S0168-9452(98)00230-1

SHELTON, A. M.; ZHAO, J.; ROUSH, R. T. Economic, ecological, food safety and social consequences of the deployment of BT transgenic plants. Annual Reviews of Entomology, v.47, p.845-881, 2002. https://doi.org/10.1146/annurev.ento.47.091201 .145309

SHEWRY, P. R. Improving the protein content and composition of cereal grain. Journal of Cereal Science, v.46, p.239-250, 2007. https://doi.org/10.1016/i.jcs.2007.06.006

SHRAWAT, A. K.; CARROLL, R. T.; PAUW, M.; TAYLOR, G.; GOOD, A. G. Genetic engineering of improved nitrogen use efficiency in rice by the tissue-specific expression of alanine aminotransferase. Plant Biotechnology Journal, v.6, p.722-732, 2008. https://doi.org/10.1111/j.1467-

7652.2008.00351.x

ZHANG, C. S.; LU, Q.; VERMA, D. P. S. Removal of feedback inhibition of $\Delta^{1}$-pyrroline-5-carboxylate synthetase, a bifunctionalenzyme catalyzing the first 2 steps of proline biosynthesis in plants. Journal of Biological Chemistry, v.270, n.35, p.20491-20496, 1995.

ZHOU, Y.; CAI, H.; XIAO, J.; LI, X.; ZHANG, Q.; LIAN, $X$. Overexpression of aspartate aminotransferase genes in rice resulted in altered nitrogen metabolism and increased amino acid content in seeds. Theoretical and Applied Genetics, v.118, p.1381-1390, 2009. https://doi.org/10.1007/s00122-009-0988-3
Recebido para publicação em 29/10/2018

Revisado em 28/01/2019

Aceito em 06/02/2019 